\title{
EXPERIÊNCIAS DO TEMPO VIVIDO: REFLEXÕES DE JOVENS ESTUDANTES DO INTERIOR DO BRASIL SOBRE A VIDA NA PANDEMIA DE COVID-19 E A ESCOLA COMO ESPAÇO DE SOCIABILIDADE
}

\author{
MARINA JORGE DA SILVA ${ }^{1}$ \\ JOICE BISSOLOTI BRIGATI ${ }^{2}$ \\ Lívia CELEGATI PAN ${ }^{3}$
}

\begin{abstract}
RESUMO
A pandemia de Covid-19 e a grave crise de ordem sanitária, econômica e social que dela decorre tem impactado as juventudes de distintas formas. Enfocando a realidade brasileira buscou-se conhecer como estudantes de ensino médio de uma cidade de pequeno porte do interior do estado de São Paulo vêm lidando com o momento atual, por meio da realização de Oficinas de Atividades, Dinâmicas e Projetos desenvolvidas de maneira híbrida, que evidenciaram que a maior dificuldade recai sobre a sociabilidade desses jovens. Entende-se a escola como espaço de suporte social a esses sujeitos e suas demandas, concorrendo para seu cuidado e atenção ${ }^{4}$.
\end{abstract}

$$
\begin{aligned}
& \text { PALAVRAS-CHAVE: JUVENTUDES, ESCOLA PÚBLICA, SOCIABILIDADE, COVID-19, } \\
& \text { EDUCAÇÃO BÁSICA }
\end{aligned}
$$

${ }^{1}$ Doutorado em Terapia Ocupacional pela Universidade Federal de São Carlos (PPGTOUFSCar). Professora da Universidade Federal de São Carlos-SP/Brasil. Contato: marinajorge@ufscar.br

${ }^{2}$ Mestrado em Ciências pela Universidade São Paulo (USP-ESALQ). Professor de Educação Básica II-Secretaria da Educação do Estado de São Paulo. Ibaté-SP/Brasil. Contato: joicebbrigati@gmail.com

${ }_{3}^{3}$ Doutorado em Terapia Ocupacional pela Universidade Federal de São Carlos (PPGTOUFSCar). Professora da Universidade Federal de São Carlos-SP/Brasil. Contato: liviapan@ufscar.br

${ }^{4}$ A doutrina jurídica da Proteção Integral é trazida no artigo 227 da Constituição Federal, onde se declara ser dever da família, da sociedade e do Estado assegurar, à criança e ao adolescente, com absoluta prioridade, o direito à vida, à saúde, à alimentação, à educação, ao lazer, à profissionalização, à cultura, à dignidade, ao respeito, à liberdade e à convivência familiar e comunitária, além de colocá-los a salvo de toda forma de negligência, discriminação, exploração, violência, crueldade e opressão. No Estatuto da Criança e do Adolescente aparece esta doutrina reafirmada sob três princípios: o reconhecimento da condição peculiar de pessoa em desenvolvimento, de sujeito de direitos e absoluta prioridade como um compromisso público e jurídico (Brasil, 1988; Brasil, 1990). 


\title{
EXPERIENCIAS DEL TIEMPO VIVIDO: REFLEXIONES DE JÓVENES ESTUDIANTES DEL INTERIOR DE BRASIL SOBRE LA VIDA DURANTE LA PANDEMIA DE COVID-19 Y LA ESCUELA COMO ESPACIO DE SOCIABILIDAD
}

\begin{abstract}
RESUMEN
La pandemia de COVID-19 y la grave crisis sanitaria, económica y social resultante han afectado a las juventudes de diferentes maneras. Centrándonos en la realidad brasileña, buscamos conocer cómo los estudiantes de enseñanza media de una pequeña ciudad del interior del estado de São Paulo han estado enfrentando el momento actual, a través de la implementación de Talleres de Actividades, Dinámicas y Proyectos desarrollados de manera híbrida, que mostraron que la mayor dificultad radica en la sociabilidad de estos jóvenes. La escuela se entiende como un espacio de apoyo social para estos sujetos y sus demandas, contribuyendo a su cuidado y atención.

PALABRAS CLAVE: JUVENTUDES, ESCUELA PÚBLICA, SOCIABILIDAD, COVID-19, EDUCACIÓN BÁSICA

\section{EXPERIENCES OF LIVED TIME: REFLECTIONS OF YOUNG STUDENTS FROM THE INTERIOR OF BRAZIL ABOUT LIFE DURING THE COVID-19 PANDEMIC AND SCHOOL AS A SPACE OF SOCIABILITY}

\begin{abstract}
The Covid-19 pandemic and its resulting serious sanitary, social, and economic crisis have affected young people in several different ways. Focused on the Brazilian reality, we aimed to gain an insight on how high school students from a small town in the interior of Sao Paulo (state) have been facing the current situation through the implementation of Workshops, Dynamics and Projects developed in a hybrid way, which showed that the most difficult part of implementing them lies on the sociability of these young people. School is understood, therefore, as a space of social support to these individuals and their demands, contributing to their attention and care.
\end{abstract}

KEYWORDS: YOUTHS, PUBLIC SCHOOL, SOCIABILITY, COVID-19, PRIMARY EDUCATION 


\section{INTRODUÇÃO}

Com o início da pandemia causada pelo vírus SARS-CoV-2 evidenciouse ainda mais as desigualdades estruturais da nossa sociedade e agravou-se uma desproteção social (Sposati, 2020), para muitos, já pré-existente. A Covid-19 lançou luz sobre essas desigualdades ao se distribuir de diferentes modos pelo país, marcando de forma distinta grupos populacionais e afetando de modo mais intenso àqueles moradores de territórios pobres e vulneráveis, com menor acesso à informação, aos recursos para cuidados de higiene e prevenção da doença (Santos, 2020), e dificultando ou mesmo impossibilitando, de forma equânime, a adoção de medidas de autopreservação.

Considerando que os jovens compõem o conjunto social sobre o qual incidem, com maior intensidade, os dilemas contemporâneos da construção histórica da realidade social (Melluci, 1997), pensar o estado de anormalidade e crise que estamos atravessando em virtude da pandemia por Covid-19, bem como os impactos produzidos sobre as juventudes, é algo atual e de grande importância.

Tomando as desigualdades sociais como um fator de impacto na produção de vivências e experiências nas/das juventudes (Lopes et al., 2008), no que tange seu efetivo exercício de cidadania e acesso aos direitos sociais e de participação na vida pública (Telles, 1994), destaca-se que a pandemia de COVID-19 traz ainda maiores implicações àqueles sujeitos em situação de vulnerabilidade social (Castel, 1998).

Para Telles (1994), existe uma lógica silenciosa da exclusão culminando em um processo que descredencia os pobres de qualquer possibilidade de participação efetiva na sociedade. Portanto, em se considerando que é sobre a juventude pobre que incide ainda com maior nitidez a face da exclusão das juventudes brasileiras, torna-se ainda mais pertinente e importante refletir acerca dos desdobramentos da pandemia na intersecção com a questão da vulnerabilidade. 
Diante desse cenário de tantos limites e desigualdades entende-se que a escola tem potencial para ocupar um papel de centralidade no enfrentamento das vulnerabilidades sociais, colocando-se, para além da tarefa do ensino pedagógico e instrumental, à reelaboração crítica e reflexiva da cultura dominante, possibilitando aos alunos que compreendam os processos aos quais estão expostos e motivando-os a contribuir para/na sociedade a partir de um exercício efetivo de cidadania (Lopes et al., 2011). Além disso, sendo um dos únicos equipamentos sociais voltado especificamente para este grupo, a escola apresenta-se como um potente aglutinador, pela possibilidade de compartilhamento de um espaço comum e, por isso, como um lócus privilegiado de fomento a experiências de convivência e sociabilidade.

Pan e Lopes (2020) destacam a necessidade e importância da reflexão e debate acerca da natureza do suporte que a escola, em conjunto com os outros serviços e equipamentos, em uma composição em rede, pode oferecer para crianças, adolescentes e jovens. Nesta direção, destaca-se a relevância deste equipamento pública de ensino na chegada junto às juventudes das classes populares, portanto, um contingente enorme de sujeitos, os quais acessam, via educação enquanto política social, perspectivas de redução da desigualdade social, histórica, cultural e econômica que nos persegue. Diante disso, pauta-se o processo de escolarização como estratégia de fomento à integração social, quer pela oferta de formação instrumental para chegada em melhores postos de trabalho, decorrendo em melhores condições de renda e vida, quer pelo seu papel social como espaço de cuidado e sociabilidade (Lopes e Malfitano, 2016).

Entretanto, o grave momento vivido pela pandemia colocou em debate a essencialidade da escola enquanto serviço. Com momentos de abertura e fechamento para as aulas presenciais se alternando em decorrência de condições sanitárias, foram previstas aulas virtuais/remotas como principal estratégia para buscar diminuir o prejuízo educacional vivenciado. Contudo, a suspensão das 
atividades escolares presenciais e sua adaptação para o formato virtual/remoto, nos convida a refletir acerca dos reflexos destas medidas sobre a vida dos alunos.

Nesta perspectiva, trazemos aqui um relato de experiência construído no bojo de uma parceria entre um Laboratório de uma universidade pública Universidade Federal de São Carlos (UFSCar) — e uma escola pública, ambas localizadas na região central do estado de São Paulo-Brasil. Desde 2004 a equipe do METUIA/UFSCar ${ }^{5}$, composta por pesquisadores, docentes de universidades públicas brasileiras, terapeutas ocupacionais e estudantes de graduação, partindo do aporte teórico e metodológico da terapia ocupacional social, tem desenvolvido ações de ensino, pesquisa e extensão com a juventude pobre, junto a escolas públicas da região de São Carlos/SP, com vistas a criação de espaços de participação democrática, ampliação das redes de sociabilidade e (re)construção de perspectivas ampliadas de futuro (Lopes e Malfitano, 2016).

Com este breve relato pretende-se pautar como a escola, especialmente a pública, vem sendo percebida pelos alunos do ensino médio como equipamento social capaz de promover experiências de sociabilidade e suporte social e, nesse sentido, como as medidas adotadas para a prevenção do SARS-CoV-2 no âmbito da Educação Básica, tais como o fechamento temporário dos espaços escolares e o revezamento para aulas presenciais, associadas ao impacto social da pandemia, têm gerado processos de abandono e evasão escolar (Sobrinho Jr. e Moraes, 2020).

${ }^{5}$ O Projeto Metuia, criado em 1998 e atualmente sob a denominação Rede Metuia, se constitui como um grupo interinstitucional de estudos, formação e ações pela cidadania de grupos em processo de ruptura das redes sociais de suporte (Barros et al., 2002), tendo como proposta o desenvolvimento de projetos no âmbito do ensino, da pesquisa e da extensão em terapia ocupacional social e em sua interconexão com diferentes setores (Lopes e Malfitano, 2016). A sigla METUIA/UFSCar é tanto uma referência ao Núcleo UFSCar do Projeto Metuia, quanto ao Programa de Extensão METUIA-Terapia Ocupacional Social e ao Laboratório de Pesquisa METUIA do Departamento de Terapia Ocupacional e do Programa de Pós-Graduação em Terapia Ocupacional ambos da UFSCar. 


\section{Caracterização}

A experiência aqui apresentada foi desenvolvida entre os meses de abril e junho de 2021 em uma escola pública de uma cidade de pequeno porte ${ }^{6}$ no interior do estado de São Paulo ${ }^{7}$, no Brasil. De acordo com Melo e Silva (2007), esta cidade ilustra uma opção de desenvolvimento que, historicamente, têm privilegiado os grandes conglomerados econômicos, em detrimento do suporte às necessidades básicas de reprodução vida de grande parte da população, fazendo com que um contingente importante da população se coloque em situação de subemprego ou desemprego e, por conseguinte, em condições materiais bastante precárias de subsistência.

O território de inserção e entorno da escola onde se deu a experiência ilustra bem este contexto apresentado pelas autoras (Melo e Silva, 2007), sendo vulnerável, e materializando desigualdades nas condições de vida e viver dos moradores $^{8}$. Isso ficou bastante evidente quando, em 2020, deflagrada a pandemia de Covid-19, houve a necessidade de adaptação das aulas para a forma remota, através do uso das tecnologias de comunicação.

\footnotetext{
${ }^{6}$ Segundo o Instituto Brasileiro de Geografia e Estatística (IBGE), a ideia de pequeno porte abarca cidades com população abaixo de 50 mil habitantes (IBGE, 2001), sendo que o município em questão atualmente tem uma população estimada em 35.830 pessoas.

${ }^{7} \mathrm{O}$ estado de São Paulo está situado na região sudeste do Brasil e caracteriza-se por ser o estado mais populoso e considerado o centro financeiro e econômico do país, responsável por quase $30 \%$ do PIB.

${ }^{8}$ De acordo com dados fornecidos pela gestão escolar, o número de estudantes em situação de pobreza ou extrema pobreza cresceu mais de $29 \%$ no último ano. Este número refere-se aos estudantes oriundos de famílias registradas no Cadastro Único (CadÚnico), um sistema criado pelo Governo Federal, mas operacionalizado e atualizado pelas prefeituras municipais, com vistas ao acompanhamento das famílias de baixa renda no Brasil e facilitação de seu acesso a vários programas sociais. https://www.gov.br/pt-br/servicos/inscrever-se-no-cadastro-unico-para-programassociais-do-governo-federal.
} 
Por falta de acesso de muitos estudantes aos recursos necessários (celulares, computadores e redes de internet) e/ou pela necessidade de procurar trabalho frente ao agravamento ${ }^{9}$ da crise econômica pré-existente e persistente e/ou, ainda, pela falta de estímulo familiar para continuidade dos estudos, muitos jovens deixaram de frequentar a escola neste período. Assim, a gestão escolar tem criado e recriado estratégias a fim de possibilitar que os alunos com maior necessidade pudessem acessar a escola e frequentá-la presencialmente. Nesta perspectiva, diante da regulamentação do Governo do estado de São Paulo, vigente naquele momento ${ }^{10}$, para revezamento dos estudantes no acompanhamento das aulas ora presencialmente, ora de forma remota, foram priorizados para frequentar presencialmente as aulas aqueles que apresentavam necessidade de alimentação escolar; dificuldade de acesso à tecnologia e outros suportes essenciais para acompanhamento das aulas na modalidade remota; severas defasagens de aprendizagem; aqueles cujos responsáveis trabalham em serviços essenciais; ou, ainda, aqueles considerados com algum risco à sua saúde mental.

Com esta organização, a unidade que atenderia, presencial e diariamente, 330 estudantes, recebia naquele momento cerca de 99 jovens (30\%), distribuídos em onze diferentes séries sendo que, destes, acompanhavam as aulas no ensino remoto, de modo síncrono, aproximadamente 56 alunos (17\%), enquanto o

\footnotetext{
${ }^{9}$ Particularmente no Brasil essa situação vem se agudizando na somatória da conjuntura política ao contexto sanitário. A priorização do mercado financeiro que, largamente, vem sendo defendida enquanto ideologia e estratégia, apresenta uma perspectiva da economia em oposição às demandas sociais, acentuando e agravando reprodução de desigualdades sociais no país.

${ }^{10}$ As aulas e atividades presenciais, no contexto de pandemia de Covid-19, nas escolas públicas do estado de São Paulo - Brasil, no momento da escrita deste artigo estavam regulamentas pelo Decreto n. ${ }^{\circ}$ 65.384, de 17 de dezembro de 2020 (São Paulo, 2020). Dispondo sobre a retomada das aulas e atividades presenciais, de forma gradual e não obrigatória, o referido Decreto (São Paulo, 2020) pautava-se na classificação de risco para adoção de medidas restritivas de controle e combate ao coronavírus; logo, nas fases de maior restrição, como quando se deu esta experiência, era possível ter $35 \%$ dos estudantes matriculados frequentando a escola presencialmente.
} 
demais, 175 jovens (53\%) deveriam assistir às aulas de forma assíncrona, realizando as atividades pelo aplicativo utilizado pela Secretaria de Estado da Educação de São Paulo, desenvolvido com o objetivo de ampliar a oferta aos alunos de uma educação mediada por tecnologia, de forma inovadora, com os dados móveis patrocinados. Entretanto, alguns alunos ficaram sem acompanhar as aulas, apresentando ruptura com o sistema escolar durante o período de suspensão das aulas presenciais em 2020.

Somado à preocupação com esses adolescentes e jovens, a equipe escolar passou a identificar e a receber dos alunos, que de alguma maneira (presencial ou remotamente — de modo síncrono ou assíncrono) se mantiveram presentes e ativos, a demanda para que houvesse um espaço de cuidado e diálogo em relação às suas vivências da/na pandemia. Com isto, diante da parceria já instituída com o METUIA/UFSCar, desenvolveu-se a proposta de realização de oficinas para este fim específico.

Tomando como pressuposto a participação e colaboração dos estudantes, foram planejadas Oficinas de Atividades, Dinâmicas e Projetos, objetivando acolher suas necessidades e fazendo-os ativos em todas as etapas do processo, desde a definição de quais eram os temas mais relevantes para serem trabalhados, até a realização da análise e o uso que será feito como desdobramentos desses encontros.

As Oficinas de Atividades, Dinâmicas e Projetos são uma das tecnologias sociais ${ }^{11}$ desenvolvidas pela e para a intervenção em terapia ocupacional social. Constituindo-se como estratégia de intervenções coletivas; parte-se do uso de atividades diversas como um recurso facilitador na/da aproximação com os(as) jovens, ou, dito de outra forma, um mediador do trabalho de aproximação, e

\footnotetext{
${ }^{11} \mathrm{Na}$ terapia ocupacional social toma-se como referência a compreensão de tecnologia social (LOPES et al., 2014) como técnicas e metodologias voltadas para a transformação e inclusão social (BAVA, 2004; DAGNINO et al., 2004).
} 
apreensão de conteúdos e demandas (Barros, 2004; Barros, Ghirardi e Lopes, 2002). Dentre um dos objetivos colocados para essas Oficinas está a produção de espaços de reflexão e debate sobre os cotidianos e as realidades dos participantes, visando processos de conscientização parametrizados pelas noções de cidadania, de direitos/deveres e da participação democrática (Lopes et al., 2014).

Deste modo, articulada à possibilidade de uma postura protagonista no enfrentamento das possíveis dificuldades vivenciadas, pensou-se nas Oficinas de Atividades, Dinâmicas e Projetos como espaços protegidos de escuta e cuidado aos/às jovens, buscando incluir os estudantes que estavam frequentando as aulas presencialmente, bem como àqueles que se mantinham no formato online/remoto, sendo uma atividade sugerida, portanto, não obrigatória, partindo do entendimento que a atratividade desta ação estaria posta pela necessidade sentida por cada jovem.

Assim, como principal objetivo, buscou-se compreender como os/as participantes dessas ações estavam vivendo a pandemia de Covid-19, quais os impactos em seus cotidianos e, sobretudo, dialogar sobre quais estratégias utilizavam para o enfrentamento das dificuldades identificadas, buscando o compartilhamento de experiências entre eles/elas, busca de soluções alternativas e conjuntas, fomentando o apoio mútuo e o fortalecimento da escola como um espaço de acolhimento e cuidado para as suas demandas.

Destaca-se que permeou todo o processo de construção desta experiência a preocupação ética acerca de fazê-la adequada em todos os seus aspectos, o que inclui relacionar-se com o outro, o interlocutor, respeitando-o como pessoa e cidadão (Teixeira; Oliveira, 2010). Dessa forma, a responsabilidade com e nas Oficinas realizadas aproximam-se da discussão da ética nas construções coletivas e processuais, teóricas e práticas dos/nos projetos que vimos, como grupo, empreendendo. Nesta direção, resgata-se Freire (1996) e a compreensão de que 
a ética é indispensável ao existir, à «presença consciente no mundo» (Freire, 1996: 09), e à convivência humana.

\section{DESENVOLVIMENTO DA EXPERIÊNCIA}

Utilizando-se das Oficinas de Atividades, Dinâmicas e Projetos como metodologia de trabalho, foram realizados encontros com alunos do último ano do ciclo II do ensino fundamental (EF) e alunos do ensino médio (EM), abrangendo adolescentes e jovens com idades entre 13 e 18 anos. Assim, foi realizado um encontro com cada uma das duas turmas de $9^{\circ}$ ano (EF) e um encontro com a turma de $1^{\circ}$ ano (EM), um com a turma de $2^{\circ}$ ano (EM) e um com a turma de $3^{\circ}$ ano (EM), totalizando cinco encontros.

A estratégia de organizar os encontros por turmas/séries seguiu a premissa de reunir um número seguro de pessoas no mesmo ambiente, com convívio mais rotineiro e, também, poder aproximar meninos e meninas com uma convivência prévia, anterior à pandemia, facilitando as trocas e o reconhecimento de um espaço mais propício a se colocarem. Desta forma, desenvolveu-se cada encontro com base em um mesmo objetivo: identificando o contexto pandêmico como um atravessamento importante em suas vidas cotidianas, (re)conhecer como aqueles estudantes vinham/vêm lidando com o momento atual.

Cada encontro tinha a duração média de 50 minutos e foi realizado de maneira híbrida, com alguns adolescentes e jovens presencialmente no espaço escolar (neste caso participavam coletivamente, dividindo equipamentos/recursos da própria escola-computador e rede de internet), outros em domicílio, participando de maneira remota, assim como a equipe que, por parâmetros institucionais da universidade, não estava autorizada para realização de ações presenciais. 
Iniciando cada encontro, era realizada uma rodada de apresentação de todos os participantes. Em seguida, era apresentado o tema da discussão e introduzida a estratégia: a produção coletiva de uma representação gráfica inspirada no Mapa Corporal, que pudesse desvelar a(s) formas(s) como aqueles(as) atores estavam/estão vivendo este período da pandemia.

De acordo com Gestaldo et al. (2012), o Mapa Corporal ou Body mapping pode ser entendido como uma nova abordagem às metodologias visuais. Originalmente, utiliza-se de um desenho de corpo humano, em tamanho real, o qual vai sendo preenchido pelo uso de escrita, desenho, pintura ou outras técnicas artísticas, com vistas representar aspectos da vida cotidiana (Gestaldo et al., 2012), e/ou comunicar conteúdos levantados a partir de uma pergunta e/ou tema disparador. Em nosso caso, com o encontro híbrido, utilizou-se como recurso a Jamboard, uma lousa interativa do Google Meet ${ }^{\circledR}{ }^{12}$, para responder a seguinte questão: «como você está vivendo a pandemia?».

Dados os limites do recurso virtual, optou-se por dividir a discussão em cinco partes, todas relativas ao momento vivido na/pela pandemia, a saber: a) o que acontece à sua volta - para que os(as) jovens pudessem dizer como leem seu entorno e contexto social; b) o que se passa em sua cabeça/mente — para que pudessem comunicar seus pensamentos e ideias; c) o que se passa em seu corpopara que pudessem dizer de suas sensações; d) o que se passa em seu coração, para que pudessem dizer sobre seus sentimentos; e) se/como a escola pode ajudar de alguma maneira no enfrentamento do momento vivido.

Com esta proposta, a perspectiva era facilitar o estabelecimento de diálogo entre os participantes, de modo que pudessem se comunicar

12 Os encontros foram realizados no formato híbrido, juntando alguns jovens que estavam presencialmente no espaço escolar e outros que participaram de forma remota, via aplicativo Google Meet ${ }^{\circledR}$, assim como a equipe que conduziu os encontros. 
criativamente por meio de um processo reflexivo e coletivo e, assim, gerar uma representação visual de como têm vivido este momento de crise.

A edição da Jamboard foi liberada para todos os presentes na sala, para que o quadro pudesse ser preenchido concomitantemente por todos(as) os(as) participantes. Diante da dificuldade de alguns, uma pessoa da equipe se colocou à disposição para preencher a lousa conforme as orientações de cada grupo, com a avaliação e validação dos mesmos. Dessa maneira, além de dialógico, o encontro foi dialogado, sendo a linguagem verbal a principal via de comunicação, apesar da proposta de uso de outras linguagens, tais como a escrita.

Apesar das adaptações possíveis e necessárias para o ambiente virtual, viu-se nesta atividade, de um lado, a possibilidade dos adolescentes e jovens poderem dizer de seus afetos e reflexões e, de outro, da equipe poder acessar este conteúdo como ponto de partida para pensar estratégias de acolhimento e ações de enfrentamento às dificuldades sinalizadas, junto com a equipe gestora da escola.

\section{RESUltadOS-OS/AS JOVENS E SUAS EXPERIÊNCIAS NA PANDEMIA DE COVID-19}

De forma geral, os e as jovens relataram muitas dificuldades em relação ao momento vivido, evidenciando desde a tristeza por tantas mortes, medo de contrair o vírus e/ou ter alguém de sua família contaminado/doente, tédio pela suspensão de atividades que realizavam anteriormente, angústias em relação às incertezas do futuro contraposta à urgência em se viver o momento presente, sentido como em suspensão, e às pressões para contribuírem mais nas atividades domésticas. Ao mesmo tempo, referiram como aspecto positivo poderem se dedicar mais às atividades prazerosas, tais como ouvir música e assistir séries ou 
aprender algo novo, como cozinhar, revelando uma dualidade complexa na vivência deste período.

FIGURA 1. REPRESENTAÇ̃̃O DO BODY MAPPING DO 2ª ANO DO ENSINO MÉDIO

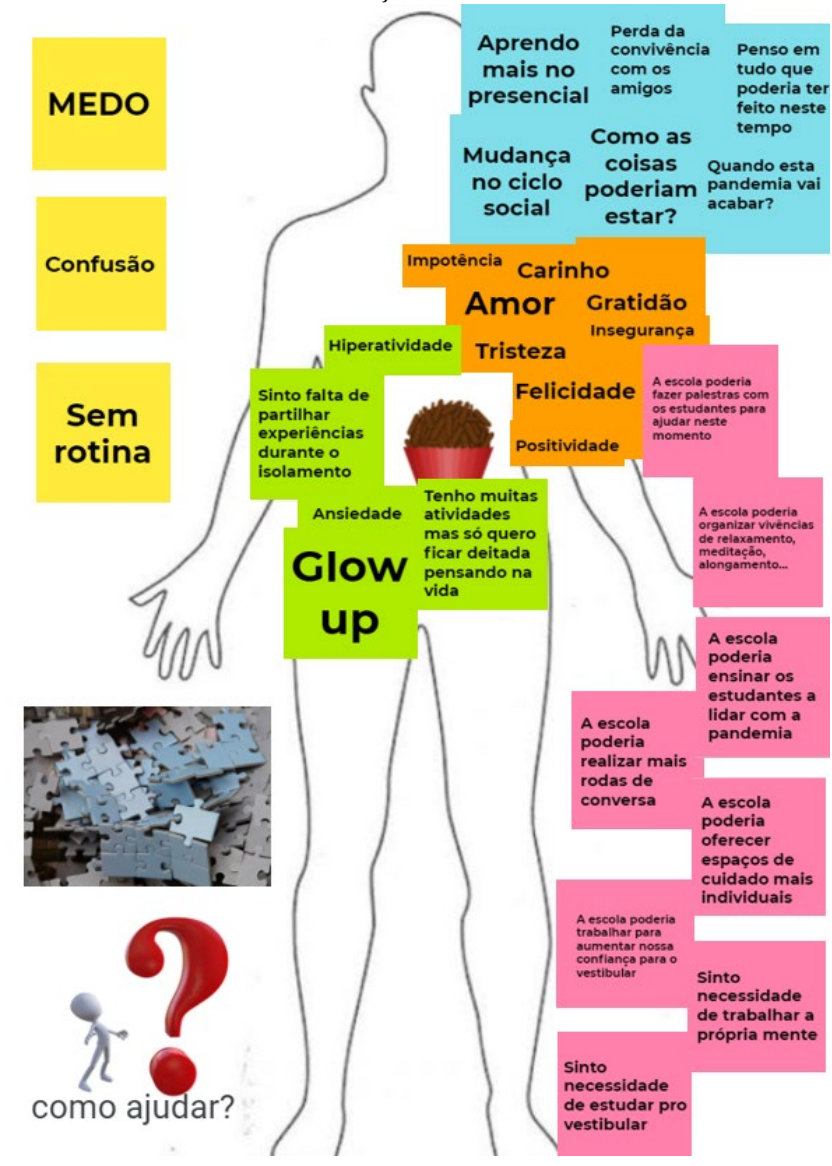

A figura acima ilustra o encontro com uma das turmas do ensino médio. Em amarelo os alunos ilustraram aspectos trazidos como exteriores a si e a seu próprio corpo, respondendo à questão «o que se passa à sua volta?». Em relação a esta categoria, nota-se questionamentos e preocupações perante a rotina, a vida e o contexto outrora conhecidos e agora tão diferentes. Aqui nota-se a perspectiva do sujeito que se coloca no trânsito entre suas questões próprias e individuais e as questões que são, ao mesmo tempo, contextuais e coletivas. Em azul os estudantes representaram as questões que têm permeado seus pensamentos; na cor laranja, as palavras que evocaram ao pensar nos sentimentos mais recorrentes 
para si no período da pandemia. Já as tarjetas verdes foram colocadas como representação de como esses adolescentes e jovens vêm sentindo, no corpo, as questões referentes a este momento vivido e, por fim, as notas na cor rosa foram utilizadas para discutir quais apoios os meninos e meninas enxergavam possíveis pela/na/a partir da escola.

Embora esta figura represente apenas um dos cinco encontros realizados, e aqui esteja sendo utilizado para ilustrar o conteúdo dos debates e as representações trazidas pelos jovens da segunda série do ensino médio, notou-se que os conteúdos foram se repetindo nas Oficinas realizadas com as outras turmas. Entretanto, há que se destacar que, das poucas diferenças notadas, se sobressai a pressão sentida, especialmente pelos alunos do $3^{\circ}$ ano do Ensino Médio por parte de seus familiares, para serem produtivos e contribuírem com a renda familiar. Tendo em vista as necessidades concretas de manutenção da vida, exigidas com o agravamento das condições socioeconômicas de parte significativa da população, alguns deles, inclusive fizeram menção de colegas que deixaram de estudar para trabalhar. Este não foi um aspecto presente nas falas e/ou representações dos alunos dos $9^{\circ}$ anos do Ensino Fundamental, o que nos leva a supor que, à medida que os jovens avançam para as séries finais, há um encurtamento da moratória social (Mannheim, 1968; Novaes, 2007; Dayrell, 2007) não apenas pela faixa etária, mas pela necessidade de composição com a renda familiar.

Para Mannheim (1968), a moratória social é um período de suspensão de obrigações e responsabilidades, defendida como elemento importante para permitir aos sujeitos suas escolhas e experimentar o mundo, marcada por uma suspensão das responsabilidades (Dayrell e Carrano, 2002). Nesta mesma direção, Abramo (2005) pauta a moratória social como um adiamento dos deveres e direitos de produção e reprodução da vida social, sendo a juventude um momento de formação para a sua futura participação. 
Em tratando-se de nosso recorte inicial: a realização de oficinas com estudantes do ensino público, existe um claro recorte de classe, uma vez que, na realidade brasileira, o acesso à escola pública dá-se, majoritariamente, para as classes populares. Desta forma, associado ao contexto político e socioeconômico do país, esses(as) jovens vão sofrendo não apenas atravessamentos em sua vida presente, mas também em relação às suas possiblidades de projeção de futuro.

Apesar de sentirem, pessoalmente, esses atravessamentos na exposição a fatores de vulnerabilidade e consequente redução de oportunidades e perspectivas de vida, é importante destacar que tratamos aqui, de um fenômeno social, cultural, política, histórica e coletivamente construído. Acreditamos que ressaltar a perspectiva social de fenômenos como a redução da moratória social para certos grupos específicos, por exemplo, favorece um enfrentamento à tendência à responsabilização e/ou culpabilização desses meninos e meninas e suas famílias (Prata e Alves Jr, 2018).

Destaca-se que a proposição de uma dinâmica mais coletiva, sob a perspectiva de valorização dessa dimensão da vida, favorece uma reflexão necessária e importante acerca do trânsito entre as dimensões individuais e coletivas de todo sujeito, na direção de não legitimar focalismos. Em nossa perspectiva, não se trata «apenas» de buscar saber como cada jovem se sente ou se move; não que isto seja pouco ou sem valor em si mesmo; antes, a abordagem coletiva nos colocou/coloca diante da perspectiva que há uma necessária abordagem entre as necessidades e demandas individuais e singulares à promoção dos espaços coletivos dos/entre os adolescentes e jovens (Malfitano e Adorno, 2006), sendo, cada um deles, concomitantemente, sujeitos individuais e coletivos.

De acordo com uma das gestoras, em momento de avaliação da intervenção com a equipe, a experiência favoreceu que os envolvidos relativizassem seu ponto de vista, uma vez que «perceberam que não é 
exclusividade deles esses sentimentos»». Este trânsito entre as dimensões individual e coletiva coloca-se como um desafio a todos os envolvidos, profissionais, e adolescentes e jovens participantes, pois, se não confrontados com essa perspectiva, tendemos, por nossa formação histórica e cultural, demarcar individualismos ao pensar o contexto apenas a partir da própria realidade, especialmente neste momento em que adquire ainda maiores destaques e relevância o discurso do peso da responsabilidade social no controle do risco de disseminação do novo coronavírus e da pandemia.

Atualmente tem se praticado muito, talvez até indiscriminadamente, o discurso que associa a responsabilidade individual, em relação à observação das medidas de segurança, às medidas de cuidado da coletividade. É certo que há, reconhecidamente, um intrínseco aspecto comunitário no cumprimento do isolamento social; entretanto, é importante que isso seja lido a partir do contexto sócio-histórico em que o sujeito está inserido pois, há uma problematização necessária na compreensão que quanto mais se cumpre o distanciamento social, mais revela-se o grau de comprometimento recíproco entre os indivíduos (Pinto, 2020). Afinal, como ignorar as condições desiguais que cada sujeito tem para lidar com este contexto?

Tomando as formulações de Castel (1998) para quem a questão social se configura nas sociedades capitalistas nas contradições entre o capital e o trabalho, se manifestando das mais variadas formas, tais como pobreza, miséria, desemprego etc., retoma-se aqui a importância e pertinência em se destacar as vulnerabilidades a que estão expostos jovens populares urbanos, contrapondo-se à recorrente suposição de que a situação de exclusão decorre de uma incapacidade de articulação e mobilização por partes desses sujeitos ou, dito de outra forma, à frequente ideia que culpabiliza o pobre pela sua condição social, visão que reforça, negativamente, sua imagem social, em decorrência da limitação de acessos a diferentes espaços e bens sociais, como sugerem Pereira e 
Malfitano (2014) e Sposito (2007). Na intersecção com a questão da vulnerabilidade, fica evidente que, independentemente de uma pandemia, por questões estruturais, os mais vulneráveis sempre serão mais atingidos.

Logo, em se considerando a juventude pobre-nomeação utilizada intencionalmente para, como sugerem Sposito e Corrochano (2005), explicitar a questão de classe social que incide sobre as possibilidades de vida e recursos acessíveis a este grupo, torna-se ainda mais central e importante.

Não há, por exemplo, como desconsiderar as diferentes realidades sociais e materiais nas ações propostas para o enfrentamento da pandemia. É categórico, por exemplo, considerar que muitas famílias vivenciam precariedade de condições de habitação, as quais se colocam na contramão do combate ao vírus (Barbosa e Neis, 2020). Com isto, mesmo as orientações que parecem simples e universais em termos de realização, constituem-se em um grande desafio para uma parcela importante da população brasileira, evidenciando desigualdades estruturais em nossa sociedade (Pires, 2020).

Esta discussão ocupou um espaço importante nos encontros com os estudantes pois, por diversas vezes relataram um sentimento de ambivalência frente à pandemia; ambivalência que decorria do reconhecimento de um certo privilégio por parte de alguns frente aos riscos para os quais outros estavam mais expostos. Embora a totalidade dos jovens ouvidos relatasse dificuldades em relação ao ensino remoto, apareceu na fala de grupos distintos a identificação que dispor de recursos para acessar este tipo de aula em si só já se constituía em um diferencial. No entanto, os(as) jovens ainda pontuaram questões de moradia e possibilidade de manutenção da renda de seus neste período como motivos de gratidão, afinal, identificam alguns colegas da própria turma que ou deixou a escola ou tem deixado muitas tarefas a fazer em virtude de ter iniciado um trabalho neste período da pandemia. 
«Sabe, dona, só de estar vivo a gente já tem que estar grato». Este foi o discurso de uma aluna durante o encontro com uma das turmas; discurso este endossado por um dos colegas ao relatar que «Por estar na escola também [tem que ser grato]; nunca achei que ia sentir tanta falta...tem gente que não vai voltar porque precisou começar a trabalhar na pandemia».

Algo interessante que se desdobrou desta discussão foi uma reflexão acerca do que se fazer com/a partir desse privilégio. Pelo incômodo frente a evasão já sabida de alguns pares, associada ao afeto pelos colegas, um grupo de estudantes ficou de encaminhar ao Grêmio Estudantil uma proposta de busca ativa a ser empreendida na direção de saber o que se pode fazer para o retorno dos(as) colegas diante da compreensão de que a finalização dos estudos viabiliza melhores oportunidades futuras de trabalho e emprego.

A aposta no uso de uma produção coletiva, que pudesse ser representativo de cada turma, partiu também do desejo de um maior estímulo à convivência e experimentação de sociabilidade e trocas, entendendo que essas experiências têm sido subsumidas de nosso cotidiano no atual cenário pandêmico. Diante das orientações sanitárias de distanciamento social, reduziu-se muito os espaços e os interlocutores de/para convivência e trocas sociais nos espaços diversos da vida.

De acordo com uma das meninas participante das oficinas «A perda da convivência com os amigos foi das piores coisas da pandemia». Apesar das muitas dificuldades relatadas pelos alunos em relação ao ensino remoto, houve uma predominância no discurso deles em avaliar muito bem o retorno à escola, na perspectiva da possibilidade de ampliação do círculo de pessoas da convivência. De modo geral, o retorno presencial, ainda que restrito, foi entendido como significativo para promover o encontro entre os pares. Houve, ainda, quem relatasse problemas nas relações intrafamiliares, alegando 
intolerância às suas escolhas como, por exemplo, de orientação sexual. «Para mim, das piores coisas é essa pandemia da intolerância», reforçou o jovem.

Pelos encontros foi possível notar um discurso da relevância da escola para estes sujeitos, especialmente enquanto um espaço para socialização (Dayrell, 2007) e conformação das identidades, sobretudo em uma cidade de pequeno porte, onde os espaços de lazer e cultura são restritos, o espaço escolar era o principal ponto de encontro para aquela população.

Admitindo-se a relevância da rede relacional à integração social de sujeitos individuais e coletivos, à criação de espaços de pertencimento e, por conseguinte, à possibilidade de criação de suporte para enfrentamento a situações de privação social, vislumbra-se a importância de redes sólidas de sociabilidade em contraposição ao isolamento social ou à reclusão aos espaços privados da vida (Silva, 2019).

Considera-se que a sociabilidade oferece oportunidades de ampliar a rede de interlocutores dos sujeitos e de pluralizar suas possibilidades de convivência, forjando elementos de interação e integração, por meio de trocas e construções conjuntas. Partindo desta leitura, entende-se a possibilidade de atrelar à sociabilidade, a promoção da cidadania e a produção de valores tais como respeito, tolerância e solidariedade, no reconhecimento do outro e de si próprio como cidadão. Isto para lembrar que é também de política que se trata quando se busca propiciar a convivência entre os humanos; convivência que permite reconhecer as singularidades constituintes da pluralidade humana e afirmar a igualdade entre os sujeitos, na produção de um mundo comum, do bem comum. Trata-se, portanto, de endossar a luta democrática, na radicalidade do reconhecimento do outro e da busca pela sua integração social, como sujeito que tem algo a comunicar e contribuir (Silva, 2019). 
FIGURAS 2 E 3. JOVENS PARTICIPANDO DAS OFICINAS DE ATIVIDADES, DINÂMICAS E PROJETOS

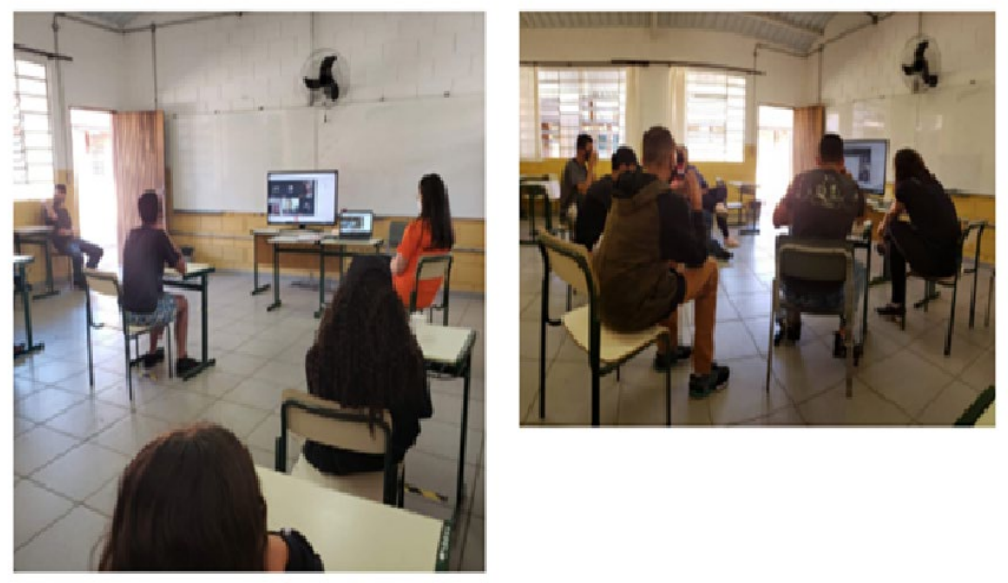

Neste aspecto reside algo importante de se destacar a partir da experiência aqui retratada: a perspectiva que os encontros, pelo seu caráter coletivo, de aproximação de sujeitos plurais, têm potencial para, a partir do fomento a sociabilidade, produzir trocas e possibilidades de ampliação de repertório, por meio do contato com o outro, deslocando e/ou colocando em perspectiva crenças, valores, desejos e modos de agir.

Uma outra faceta deste debate passa pelo questionamento acerca dos possíveis impactos para a vida desses jovens que têm experienciado a metade e/ou a maior parte do ensino médio nesse modelo híbrido/remoto, pois, para além do aspecto da sociabilidade, há de se destacar a centralidade do processo educativo para o exercício da cidadania (Marshal, 1967). Esse talvez seja um reflexo do lugar social que se atribui à escola de modo mais geral. Enquanto sociedade ainda precisamos avançar no reconhecimento desse equipamento como espaço de democratização, na medida em que a aprendizagem e a formação crítica, de todos, é parte fundamental para a participação na vida nacional (Bittar e Bittar, 2012).

Acredita-se que experiências como essa, de produção de convivência e sociabilidade, por simples que pareçam podem enriquecer a vida coletiva 
oportunizando a composição de um repertório que venha a ser utilizado pelos sujeitos, com maior criticidade e autonomia, podendo, inclusive, subsidiar a projeção de sonhos e projetos, ainda que, muitas vezes sejam frágeis diante das condições objetivas da vida como a condição socioeconômica daqueles sujeitos (Silva, 2019).

\section{Conclusões}

Buscou-se neste texto, através de uma experiência prática junto a jovens estudantes de uma escola pública de uma cidade de pequeno porte do estado de São Paulo, no Brasil, explicitar suas compreensões acerca da vivência da pandemia de Covid-19. Suas compreensões explicitam algumas controvérsias em relação ao tempo vivido: vontade de viver o presente e anseios sobre o futuro; a busca por um certo otimismo e gratidão, sem deixar de reconhecer a gravidade do que se vive; reconhecimento da importância de ficar em casa contraposta à fadiga de cumprir esta medida, entre outras.

Diante do reconhecimento da necessidade de manutenção do distanciamento social e de uma drástica redução de seu círculo social em decorrência dela, os jovens referiram-se à escola como uma possibilidade de ampliação de relações, de diálogos e trocas, pautando esse equipamento como algo de seu interesse.

Diante da restrição de repertório e de composição de redes sociais de suporte de sujeitos marcados pela vulnerabilidade social e pelo atual momento vivido, identifica-se a escola como um potente equipamento no que tange a promoção de sociabilidades, convívio com a pluralidade e de composição de uma leitura mais crítica acerca da realidade e dos fenômenos sociais. 
O alcance das ações aqui relatadas é pequeno para dizer-se representativo enquanto discurso juvenil; certamente não se ignora isso, entretanto, em se considerando a pluralidade constituinte da juventude como grupo social, entendese que a experiência aqui trazida pode servir de inspiração sobre modos de se pensar e propor ações pela/na/da e com a escola pública na direção de oferta de espaços de escuta aos meninos e meninas.

Trata-se do reconhecimento de que os e as jovens são sujeitos com valor em si, no tempo presente, com potencial e possibilidades de contribuição com a sociedade, e com conteúdos pertinentes de serem comunicados, e da legitimação da escola pública como um espaço, de um lado, para a produção de acolhimento e cuidado social que se volta para o fortalecimento de redes sociais de suporte, como meio para o enfrentamento das situações de vulnerabilidade social e, de outro, de experimentação de uma possibilidade de participação social, sobretudo no que diz respeito à produção de estratégias para seguridade da vida que se tece nas controvérsias do momento vivido e que não são exclusivos do contexto da pandemia, porém, com ela acentuados e que implicam a vida de cada um/uma.

RECIBIDO: 30 DE JUNIO DE 2021 ACEPTADO: 3 DE SEPTIEMBRE DE 2021 


\section{REFERÊNCIAS}

AdORNO, R. C. F. (2001). Capacitação solidária: um olhar sobre os jovens e sua vulnerabilidade social. São Paulo: AAPCS.

BarbosA, O. L. e NeIS, A. C. (2020). Habitação em meio à pandemia: Um debate necessário. Revista do Pet Economia Ufes, 1, 20-22.

BARros, D. (2004). Terapia ocupacional social: o caminho se faz ao caminhar. Rev. de Ter. Ocup. da Univ. de São Paulo, 15(3), 90-97.

Barros, D. D., Ghirardi, M. I. G. e Lopes, R. E. (2002). Terapia Ocupacional Social. Rev. de Ter. Ocup. da Univ. de São Paulo, 13(2), 95-103.

BAVA, S. C. (2004). Tecnologia social e desenvolvimento local. Instituto Pólis, 103-116.

CASTEL, R. (1998). As metamorfoses da questão social: uma crônica do salário. Petrópolis: Vozes.

Dagnino, R. P., Brandão, F. C. e Novaes, H. T. (2004). Sobre o marco analíticoconceitual da Tecnologia Social. In Tecnologia Social: uma estratégia para o desenvolvimento. Rio de Janeiro: Fundação Banco do Brasil.

DAyrell, J. (2007). A escola «faz» as juventudes? Reflexões em torno da socialização juvenil. Educ. Soc., Campinas, 28(100), Especial, 11051128.

Recuperado

de: https://observatoriodeeducacao.institutounibanco.org.br/cedoc/detalhe/aescola-faz-as-juventudes-reflexoes-em-torno-da-socializacaojuvenil,6801c7e6-bc0a-497a-8f90-552a31ca7039

DAyrell, J. e CARRANO, P. C. R. (2002). Jovens no Brasil: difíceis travessias de fim de século e promessas de um outro mundo. Anais... 25 $5^{\mathrm{a}}$ Reunião Anual Andep: Caxambu, 01-33.

Freire, P. (1996). Pedagogia da autonomia: saberes necessários à prática educativa. São Paulo: Editora Paz e Terra.

Gastaldo, D., Magalhães, L., Carrasco, C. e Davy, C. (2012). Body-Map Storytelling as Research: Methodological considerations for telling the stories of undocumented workers through body mapping. Recuperado de: http://www. migrationhealth.ca/undocumented-workers-ontario/bodymappin

IBGE (2001). Departamento de População e Indicadores Sociais. Perfil dos municípios brasileiros: pesquisa de informações básicas municipais-Rio de Janeiro. Recuperado de: https://biblioteca.ibge.gov.br/visualizacao/livros/liv84006.pdf

LOPES, R. E. ET AL. (2008). Juventude pobre, violência e cidadania. Saúde Soc., São Paulo, 17(3), 63-76. Recuperado de: 
https://www.scielo.br/j/sausoc/a/xDfVHWyfDB4cFsfSJnQ46Np/abstrac $\mathrm{t} /$ ?lang=pt.

Lopes, R. E. e Malfitano, A. P. S. (2016). Traçados teórico-práticos e cenários contemporâneos: a experiência do METUIA/UFSCar em terapia ocupacional social. In R. E. LOPES e A. P. S. MALFITANO (Org.), Terapia Ocupacional Social: desenhos teóricos e contornos práticos (p. 297-305). São Carlos: EDUFSCar.

Lopes, R. E., Borba, P. L. De O. e Cappellaro, M. (2011). Acompanhamento Individual e Articulação de Recursos em Terapia Ocupacional Social: Compartilhando uma Experiência. O Mundo da Saúde, 35, 233-238. Recuperado http://bvsms.saude.gov.br/bvs/artigos/acompanhamento_individual_artic ulacao_recursos_terapia.pdf

Lopes, R. E., Malfitano, A. P. S., Silva, C. R. e Borba, P. L. O. (2014). Recursos e tecnologias em Terapia Ocupacional: ações com jovens pobres na cidade. Cad. Ter. Ocup. UFSCar, São Carlos, 22(3), 591-602. Recuperado de: http://www.cadernosdeterapiaocupacional.ufscar.br/index.php/cadernos/ article/view/1114

Malfitano, A. P. S e Adorno, R. C. F. (2006). Infância, juventude e vivências nas ruas: entre o imaginário da instituição e do direito. Imaginario, São Paulo, 12(12), 15-33. Recuperado de: http://pepsic.bvsalud.org/scielo.php?script=sci_arttext\&pid=S1413666X2006000100002\&lng=pt\&nrm=iso

MANNHEIM, K. (1968). O problema da juventude na sociedade moderna. In S. BRITTO (org.), Sociologia da juventude I da Europa de Marx à América Latina de hoje (pp. 69-94). Rio de Janeiro: Zahar.

Marshall, T. H. (1967). Cidadania, Classe Social e Status. Rio de Janeiro: Zahar.

Melo, B. M. e Silva, M. A. M. (2007). História de uma pequena cidade do interior paulista. Para compreender a territorialidade local. Geografia em Atos, 2(7).

MeluCCI, A. (1997).Juventude, tempo e movimentos sociais. Revista Brasileira de Educação, 5-6. Recuperado de: http://anped.tempsite.ws/novo_portal/rbe/rbedigital/RBDE05_6/RBDE0 5_6_03_ALBERTO_MELUCCI.pdf

Novaes, R. (2007). Juventude e sociedade: jogos de espelhos. Sentimentos, percepções e demandas por direitos e políticas públicas. Sociologia especial: Ciência e Vida, 1(2), 6-15. 
PAN, L. C. e LOPES, R. E. (2020). Terapia ocupacional social na escola pública: uma análise da produção bibliográfica do METUIA/UFSCar. Cadernos Brasileiros de Terapia Ocupacional, 28(1), 207-226. https://doi.org/10.4322/2526-8910.ctoAO1760.

Pereira, P. E. e Malfitano, A. P. S. (2014). Atrás da Cortina de Fumaça: Jovens da Periferia e a Temática das Drogas. Sau. \& Transf. Soc., Florianópolis, 5(1), 27-35. Recuperado de: http://incubadora.periodicos.ufsc.br/index.php/saudeetransformacao/arti cle/view/2626/3645

PINTO, S. C. L. (2020). O aspecto desestruturante da pandemia na reconfiguração dos espaços. Problemata: R.Intern.Fil., 11(5), 276-284, ISSN2236-8612. doi:http://dx.doi.org/10.7443/problemata.v11i5.53306.

PIRES, R. R. C. (2020). Os efeitos sobre grupos sociais e territórios vulnerabilizados das medidas de enfrentamento à crise sanitária da covid19: propostas para o aperfeiçoamento da ação pública. In INSTITUTO DE PESQUisa ECONÔMICA APliCADA, Diest, No 33. Recuperado de: https://www.ipea.gov.br/portal/images/stories/PDFs/nota_tecnica/20040 8_nota_tenica_diest.pdf

Prata, H. L. e Alves Junior, E. D. (2018). A culpabilização do indivíduo, se eu, ele ou você quisermos nós conseguimos!? Filos. e Educ., Campinas, SP, 10(3), 677-694.

SANTOS J. A. F. (2020). Covid-19, causas fundamentais, classe social e território. Trab Educ Saude, 18(3), 1-7. Doi: https://doi.org/10.1590/1981-7746sol00280.

SÃo Paulo (Estado). (2014). Diretrizes do Programa de Ensino Integral. São Paulo: [s. $\quad$ n.]. $\quad$ Recuperado de: https:/www.educacao.sp.gov.br/a2sitebox/arquivos/documentos/342.pd $\mathrm{f}$

SILVA, M. J. (2019). Terapia ocupacional social, juventudes e espaço público. (Tese de Doutorado), Universidade Federal de São Carlos. Recuperado de:

https://repositorio.ufscar.br/bitstream/handle/ufscar/12216/TESE\%20M arina $\% 20 J$ orge $\% 20$ (Versao $\% 20$ final_dep $\% C 3 \%$ B3sito).pdf? sequence $=1$

Sobrinho Junior, J. F. e Moraes, C. C. P. A. (2020). COVID-19 e os reflexos sociais do fechamento das escolas. Dialogia, São Paulo, 36, 128-148. https://doi.org/10.5585/dialogia.n36.18249

Sposati, A. (2020). Covid-19 revela a desigualdade de condição da vida dos brasileiros. Rev NAU Soc., 11(20), 101-103.

Sposito, M. P. e Corrochano, M. C. (2005). A face oculta da transferência de renda para jovens no Brasil. Tempo soc., São Paulo, 17(2), 141-172. 
Recuperado

de:

http://www.scielo.br/scielo.php?script=sci_arttext\&pid=S0103-

20702005000200007\&lng=pt\&nrm=iso

Sposito, M.P. (coord.) (2007). Espaços públicos e tempos juvenis. São Paulo: Global.

TeiXeira, E. e Oliveira, I. A. (orgs.) (2010). Cuidados éticos na pesquisa. In M. I. Marcondes, E. Teixeira e I. A. Oliveira, Metodologias e técnicas de pesquisa em educação. Belém: EDUEPA.

Telles, V. S. (1994). Sociedade civil e a construção de espaços públicos. In E. Dagnino (org.), Os anos 90: política e sociedade no Brasil. São Paulo: Brasiliense. 